\title{
Lithium and the thyroid
}

\author{
Carol Paton and Dominic Beer
}

\section{Thyroid disease}

The common thyroid disorders are all autoimmune in origin, with the lifetime risk of thyroid disease being $1-2 \%$. Thyroid autoantibodies are present in $9 \%$ of the adult population and $12.7 \%$ of women, with the frequency rising steeply in women over 45 years of age (Myers \& West, 1987). In addition, $20 \%$ of the over 60 -year-olds have an abnormal (raised) thyroid stimulating hormone (TSH). The presence of both raised TSH and thyroid autoantibodies is associated with the development of clinical hypothyroidism at the rate of 5\% per year (Myers \& West, 1987).

The symptoms of hypothyroidism may develop very insidiously, the usual presenting symptoms being fatigue, lethargy, mental slowness, general aches and pains and slowness of expression and movement. Considering the vagueness of these symptoms, it is not surprising that the average duration between the initiation of symptoms and a diagnosis being made is 18 months.

\section{The thyroid and affective illness}

The relationship between illness and endocrine abnormalities is complicated and this is illustrated particularly well by the thyroid: mildly abnormal thyroid function tests (TFTs) are common in severe illness (whether physical or psychiatric) as the hypothalamus-pituitarythyroid axis struggles to maintain a steady state (Drury, 1990). They return to normal in line with general health, and intervention is rarely required. In apparent contradiction to this fact, the thyroid hormones T3 and T4 are used to augment antidepressants in treatment resistant depression (in euthyroid patients) to good effect (Bauer \& Whybrow, 1990). This approach tends to be more effective in women (Katona, 1991) and in those with rapid cycling illness (which, like thyroid disease, is more common in women; Szabadi, 1991).

Although the prevalence of thyroid dysfunction in those with affective illness is unknown, frequent associations exist between female gender, increasing age, depressive illness and thyroid dysfunction (Custro et al, 1994) and as psychiatrists investigate in order to exclude an organic component to an abnormal mental state, so endocrinologists consider the contribution of that same abnormal mental state to thyroid status. Although much remains to be understood about the relationship between the thyroid and affective illness, baseline TFTs remain an essential screening test for all patients. The results of such tests should be interpreted carefully.

\section{Effects of lithium}

As well as mild abnormalities in TFTs being common in affective illness, they are also common during treatment with lithium. TFTs should be routinely measured before initiating lithium therapy, and then six monthly throughout treatment in order that such effects can be monitored and an intervention made if clinically appropriate (see below): after 1-4 months' treatment with lithium a small euthyroid drop in T4 with associated rise in TSH is commonly seen. However, after a year, the T4 is usually back to normal and the TSH almost so (Smigan, 1984). The moral here is that mild abnormalities in TFTs associated with lithium treatment often do not require intervention, and thyroxine replacement may not be indicated. It is more prudent to monitor the TFTs monthly and prescribe replacement therapy only, if after four months' treatment the T4 continues to fall and the TSH rise, or the patient is clinically hypothyroid.

Lithium treatment can occasionally lead to goitre. The incidence is not known but it is almost certainly above the endemic one. The mechanism is probably the inhibition of T4 release leading to increased pituitary secretion of TSH which leads in turn to the proliferation of thyroid tissue.

The association between lithium therapy and hypothyroidism is well-known (Jefferson, 1990), the estimated prevalence being 3-5\%. Although the mechanism by which lithium induces this effect is not entirely clear, it is known that lithium can interfere with iodine uptake into the thyroid, therefore inhibiting the synthesis of thyroglobulin as well as inhibiting T4 release and the peripheral conversion of T4 to T3 (Jefferson, 1990). Lower doses of lithium, leading to serum levels less than $0.8 \mathrm{mmol} / 1$ are associated with less effects on the thyroid (Coppen et al, 1983). In addition, lithium is known to interfere with the functioning of Tsuppressor lymphocytes (which regulate the production of antibodies by B-lymphocytes). It is possible that this results in autoantibodies being 
- Automimmune thyroid disease is common, particularly in women.

- Mildly abnormal TFTs are common in affective illness.

- Thyroid side-effects are well documented with lithium:

- Self limiting, clinically insignificant changes in TFTs (common, see text). No intervention required.

- Goitre (incidence unknown). If unacceptable to patient, consider stopping lithium.

- Clinical hypothyroidism (prevalence 3$5 \%$ ).

- Do not stop lithium.

- Easily treated with T4 replacement.

- Reversible in majority on discontinuing lithium.

TFTs should be measured:

- As a baseline before initiating lithium.

- Three months into treatment.

- If abnormal:

- Check monthly until normal, or

- Intervention (T4 replacement) required:

- Worsening TFTs after 4 months' treatment.

- Patient clinically hypothyroid.

- If normal:

- Check 6 monthly/annually for duration of lithium therapy.

able to proliferate unchecked. Ten to $60 \%$ of those with lithium induced hypothyroidism have thyrold autoantibodies. Other autoantibodies are also more common in lithium treated patients than in the general population (Hoffman \& Pizzo, 1987).

Whether lithium causes or merely aggravates autoimmune disease is unclear, but whatever the aetiology, lithium induced hypothyroidism is easily treated by thyroxine replacement and is not an indication for discontinuing treatment (Schou, 1989). It is also reversible; within a few weeks of stopping lithium, T4 increases by an average of $25 \%$. It is entirely possible that the cases of irreversible hypothyroidism that have been reported are due to the spontaneous disorder and the same is probably also true of the relatively small number of reports of hyperthyroidism which have been associated with lithium treatment, although it is probable that lithium has a destabilising effect on any preexisting thyroid disorder.

The effects of lithium on the thyroid are well established but frequently misunderstood. $\mathrm{Ab}$ normal TFTs are common in severe physical and psychiatric illness and replacement therapy is often not indicated. True hypothyroidism can be easily treated by thyroxine and is not an indication for withdrawing lithium. There is no convincing evidence that lithium causes irreversible destruction of the thyroid.

\section{References}

BAUER, M. S. \& WHYBROW, P. C. (1990) Rapid cycling bipolar affective disorder. 11. Treatment of refractory rapid cycling with high-dose levothyroxine: a preliminary study. Archives of General Psychiatry, 47, 435-40.

COPPEN, A., ABU SALEH, M. T., Mnun, P., et al (1983) Reducing lithium dose reduces morbidity and side-effects in affective disorders. Journal of Affectue Disorders, 6. $53-66$.

CUSTRO, N., SCAFIDI, V., LO BAIDO, R. et al (1994) Subclinical hypothyroidism resulting from autoimmune thyroiditis in female patients with endogenous depression. Joumal of Endocrinology Investigations, 17, 641-646.

DRURY, P. L. (1990) Endocrinology. In Clinical Medicine leds P. Kumar \& M. Clark), pp. 764-831. Balllere Tindall.

Hofrman, F. A. \& Pizzo, P. A. (1987) The immune system. In Modern Lithium Therapy (ed. F. N. Johnson), pp. 226232. Oxford: IRL Press.

KATONA, C. L. E. (1991) Refractory depression. In The Uses of Fluavetine in Clinical Practice. International Congress and Symposium Serles No 183. London: Royal Soctety of Medicine Services.

JEFFERSON, J. W. (1990) Lithium: the present and the future. Journal of Clinical Psychiatry. B1(Suppl. 8), 4-8.

MYERS, D. H. \& WEST, T. E. T. (1987) Hormone systems. In Modern Lithtum Therapy (ed. F. N. Johnson). pp. 220226. Oxford: IRL Press.

SCHOU, M. (1989) Lthium prophylaxds: myths and realities. American Joumal of Psychiatry. 146. 573-576.

SMIGAN, L., WAHIN, A., JACOBSSON, L., et al (1984) Lthium therapy and thyroid function tests: a prospective study. Neuropsychobtology, 11, 39-43.

SZABADI, S. (1991) Thyroid dysfunction and affective illness. Brttish Medical Journal, 302, 923-924.

Carol Paton, Pharmacist, and Dominic Beer, Senior Lecturer and Hon. Consultant Psychiatrist. Bexdey Hospital, Old Bexdey Lane, Bexdey, Kent DA5 2BW 